\title{
Assessing agricultural drought management strategies in the Northern Murray-Darling Basin
}

\author{
Isabella Aitkenhead ${ }^{1,2}$ - Yuriy Kuleshov 2,3,4 (D) Andrew B. Watkins ${ }^{2}$. \\ Jessica Bhardwaj ${ }^{1,2} \cdot$ Atifa Asghari ${ }^{1,2}$
}

Received: 21 December 2020 / Accepted: 18 June 2021 / Published online: 23 June 2021

(c) Crown 2021

\begin{abstract}
The Northern Murray-Darling Basin (MDB) is a key Australian agricultural region requiring efficient Agricultural Drought Management (ADM), focused on resilience. Although a need for resilience in local farming communities has long been recognised, previous studies assessing ADM in the Northern MDB did not consider two key elements of resilient management: proactivity (preparing for drought prior to a drought event) and suitability (localised drought management targeted at decision-makers). This study assessed the current ADM Strategy (ADMS) implemented within five selected Northern MDB Local Government Areas (LGAs) (Paroo Shire, Balonne Shire, Murweh Shire, Maranoa Region, and Goondiwindi Region), specifically investigating the extent of ADMS proactivity, effectiveness, and suitability. To investigate suitability, drought risk extent of each LGA was determined. A region-specific drought risk index consisting of hazard, vulnerability and exposure indices was developed; risk mapping was conducted. All LGAs displayed very high levels of drought risk due to hazardous climatic conditions, vulnerable socio-economic attributes, and drought-exposed geographical features. A Criteria-Based Ranking (CBR) survey produced a quantitative effectiveness and proactivity rank for each major ADMS used in the Northern MDB. Government Assistance was the most proactive and effective ADMS. Strategy effectiveness ranks of the major ADMS used and drought risk extent found in each LGA were correlated to determine ADMS suitability. Overall, Balonne Shire and the Goondiwindi Region were identified as high priority areas requiring improved ADM. A user-centred Integrated Early Warning System (I-EWS) for drought could potentially increase ADM proactivity and suitability in such areas, strengthening drought resilience of farming communities.
\end{abstract}

Keywords Agricultural Drought Management Strategy $\cdot$ Australia $\cdot$ Northern MurrayDarling Basin · Climate risk · Climate resilience · Early warning system for drought . Drought preparedness

Yuriy Kuleshov

yuriy.kuleshov@bom.gov.au

Extended author information available on the last page of the article 


\section{Introduction}

Droughts are recurring features of the Australian climate, with significant impact upon communities and the economy. Severe droughts have affected large parts of eastern and southern Australia in the past decades. Recently, in 2017-2019, severe drought again impacted Queensland, New South Wales, and Victoria, including the Murray-Darling Basin (MDB) - a key agricultural region of Australia (Bureau of Meteorology 2019, 2020).

In Australia, drought monitoring is vital for informed decision-making in many sectors, including agriculture, energy, emergency services, finance, health, water management and many others. The Bureau of Meteorology $(\mathrm{BoM})$ reports on meteorological drought; BoM long-term precipitation records show that on average, widespread drought in Australia, occurs once every 18 years (Kuleshov et al. 2019). However, due to climate change impact Australia is projected to see continued decrease in cool season rainfall across many regions of southern and eastern Australia, likely leading to more time in drought (Bureau of Meteorology and CSIRO 2020). While the BoM analyses historical rainfall data and provides users with important drought information, it is state and federal government agencies which declare drought for relief and management purposes. Rainfall sub-seasonal to seasonal (S2S) forecasts are an essential part of any user-centred Integrated Early Warning System (I-EWS) for drought, providing an early warning of potential drought conditions to state and federal decision-makers (Kuleshov et al. 2020; Bhardwaj et al. 2021), and assisting users in planning their Agricultural Drought Management Strategy (ADMS).

An I-EWS for drought can enable strategic decision-making in drought-prone areas. As a result, an effective I-EWS for drought is becoming increasingly recognised as a key factor in the transition from past general crisis management approach to future resilient management of drought as a 'risk' in countries like Australia where drought frequently affects agricultural communities and economic sectors. Drought risk is the probability of adverse effects resulting from the combination of drought hazard (the potential for drought conditions and/or a drought hazard event to occur); drought exposure (the whole population, its livelihoods and resources in a place where a drought event may occur); and drought vulnerability (the likelihood of exposed factors to suffer adverse effects when a drought event occurs) (Sharafi et al. 2020). Resilient Agricultural Drought Management (ADM) not only mitigates the impacts of droughts to recover after an event has occurred but anticipates drought risk and includes the implementation of preparedness actions suited to specific at-risk areas prior to the occurrence of a drought. Resilient ADM consists of two key elements: proactivity and suitability.

In this instance, proactivity is defined as controlling a drought risk situation prior to the occurrence of a drought event, rather than responding to drought after it has occurred and reached a level of crisis. This can be achieved through ADM preparedness and adaptation, and the use of early warning information. Within this context, suitability is referring to the quality of ADM appropriateness for independent implementation in individual, local farming communities. Sufficient ADM suitability can be accomplished through locationspecific ADM Strategies (ADMSs) and stakeholder collaboration (Nguyen-Huy et al. 2020). To sufficiently shift to resilient risk management, ADM needs to be adaptively and independently maintained at the local farming community level, to ensure that ADM is adequately proactive and suitable (Nguyen-Huy et al. 2020).

Earlier studies recommend a future emphasis on drought forecasting and drought EWSs to shift away from institutional reliance and crisis management (e.g., Raikes et al. 2019). A user-centred I-EWS can inform resilient drought risk management to be appropriately 
implemented by independent farmers, with government support. The insights provided by Raikes et al. (2019) highlight the widely accepted importance of assessing the input of all key stakeholders, and of prioritising local strategies that can be easily implemented by local farming communities (Cobon et al. 2009; Connell and Grafton 2011; Paneque 2015).

Although a need for proactive and suitable management has been consistently recognised, ADM assessment studies conducted in drought-prone areas of Australia have not incorporated these elements in assessment criteria (Cobon et al. 2009; Crimp et al. 2010; Hart 2016). Thus, it is pertinent to assess the proactivity, effectiveness, and suitability of ADMSs in Australia. In this study, the assessment of these strategies has been conducted for the Northern MDB.

The MDB is Australia's largest agricultural region; the agricultural industry of the MDB is worth A \$24 billion annually [Australian Bureau of Agricultural and Resource Economics and Sciences (ABARES) 2011]. Historical climate records for the Northern MDB show that the region frequently experienced severe drought conditions [Australian Bureau of Statistics (ABS) 1988]. In 2017-2019, the Northern MDB was again affected by a severe drought, with record low rainfall in many parts of the region (Fig. 1). It is projected (with probability between 50 and $90 \%$ ) that lower rainfall and higher evaporation will be common in the Northern MDB due to future climate change, and therefore drought frequency is expected to increase (Phelps and Kelly 2019).

Due to its drought-prone nature and national economic value, the Northern MDB especially requires efficient drought management (Hart 2016). Efficient drought management consists of ADMSs that are resilient, with a focus on proactivity and suitability. Specifically, efficient ADMSs would consist of proactive risk mitigation measures considering public outreach and resource stewardship; consolidate risk knowledge and early warning information to inform evidence-based responses; concentrate on effective stakeholder

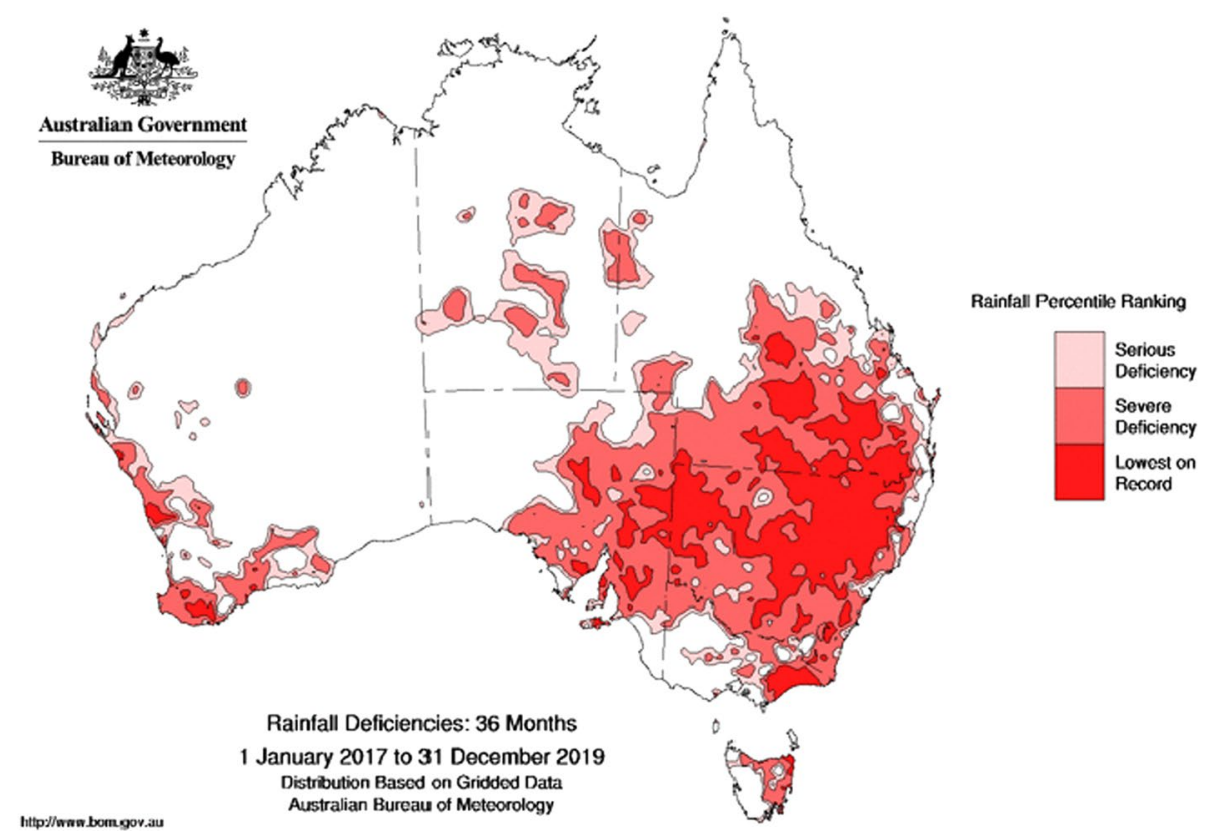

Fig. 1 Thirty-six-monthly rainfall deficiency for Australia 
collaboration between state officials and local communities to implement user-centred actions; and incorporate comprehensive governmental financial strategies to support selfsustainable drought management by local individuals (Wilhite 2005).

The key stakeholders responsible for ADM in the Northern MDB include government officials, local council officials, local farmers, and farming associations (Docker and Robinson 2014). Currently, these stakeholders play a part in the implementation of three major ADMSs within the Northern MDB: (i) the MDB Plan, (ii) the use of Water Trading, and (iii) Government Assistance (resources and financial) (Crimp et al., 2010; Docker and Robinson, 2014). The resilience of these strategies is restricted due to major limitations (for details, see "Appendix 1") which may reduce the extent of their proactivity and suitability.

Earlier studies analysing the three major ADMSs used in the Northern MDB suggested that the capacity for resilience of local farming communities is inconclusive, as it is unclear whether current ADMSs are proactive and suitable (Kirby et al. 2014; Pittock and Connell 2010). Assessment of the proactivity and suitability of strategies is therefore required to ensure that key stakeholders can respond to drought in a resilient capacity (Crimp et al. 2010).

Regions within the Northern MDB that are of particular interest include the LGAs of Balonne Shire, the Goondiwindi Region, the Maranoa Region, Murweh Shire and Paroo Shire (Fig. 2). These five LGAs strongly depend on agricultural productivity and have been severely affected by drought in the past (Pittock and Connell 2010). Future drought events are expected to have significant impacts on the agriculture sector and functionality of communities within these LGAs (Quiggin et al. 2010).

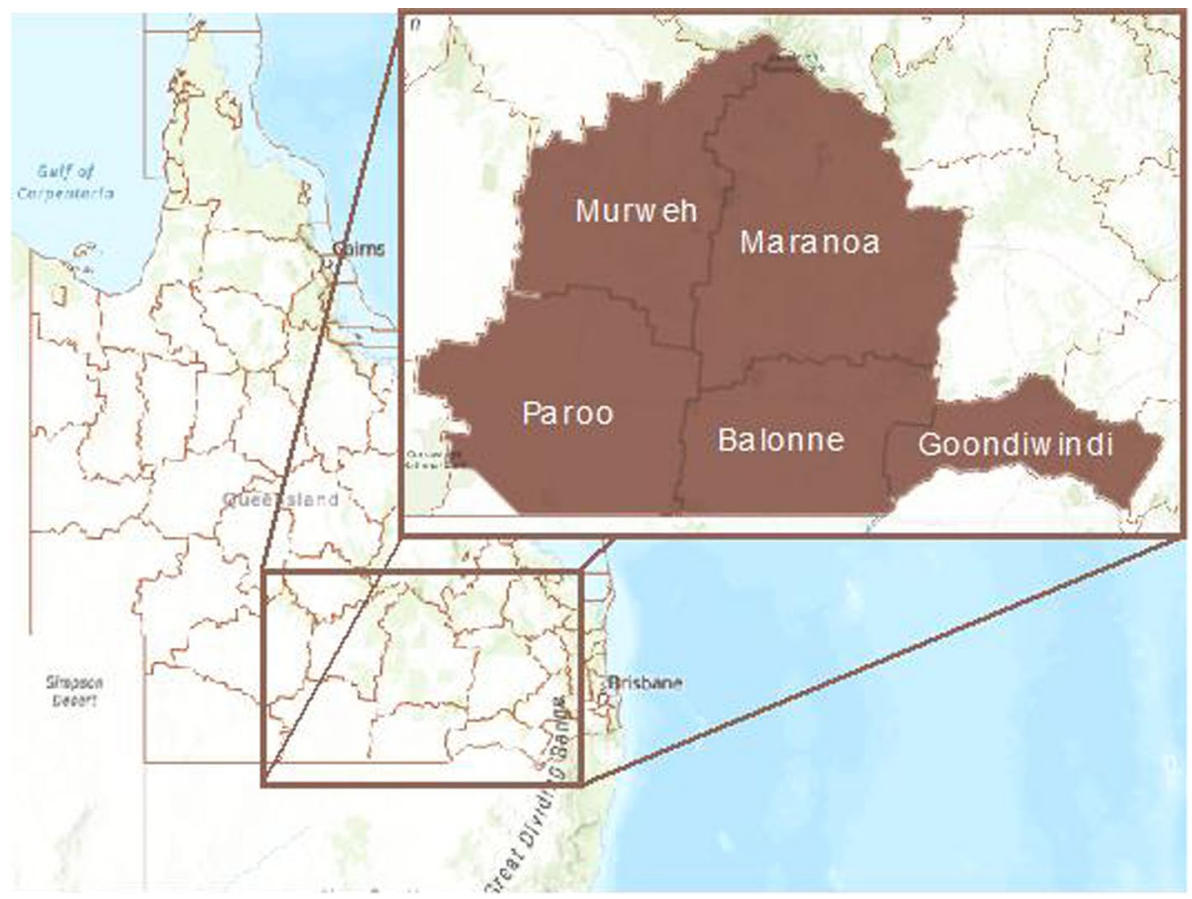

Fig. 2 Spatial extent showing the five LGAs-Balonne Shire, Goondiwindi Region, Maranoa Region, Murweh Shire and Paroo Shire-in the context of Queensland 
Assessing the proactivity and suitability of ADMSs within these five areas is of critical importance for indicating the extent of resilience to drought both in the farming communities of these LGAs and, more broadly, within the Northern MDB (Power and Cacho 2014). An accurate assessment of drought risk would be useful to inform stakeholders on the suitability of drought management decisions used within each of these Northern MDB LGAs (Yin et al. 2014). Drought risk is the chance of severe impacts on community functionality over a specific period of time, caused by drought hazard conditions combining with vulnerable social conditions, leading to significant negative human, material, economic, or environmental effects requiring an emergency response to ensure recovery (IPCC 2012).

Drought risk consists of three key components: drought hazard, drought vulnerability, and drought exposure. Drought hazard is the potential happening of a drought event which may cause an increased death rate, or other related health affects as well as adverse effects for property, infrastructure, livelihoods, and environmental resources (IPCC 2012). Drought vulnerability is the impact which a drought event may have on people, infrastructure, and the economy within communities). Drought exposure is defined as the quantity and/or location of assets and/or the elements present in areas subject to drought hazard conditions that are exposed to potential losses caused by the adverse effects of a drought event (Van Lanen et al. 2017).

Risk mapping in Geographic Information Systems (GIS) is a common method used to indicate drought hazard, vulnerability and exposure levels, as well as overall risk, and inform increasingly resilient ADM in drought-prone regions around the world (Dayal et al. 2018). However, there has been no evident drought risk mapping solely for agricultural drought on an LGA level within these five Northern MDB LGAs (Hart 2016). Drought risk mapping is valuable for use in the Northern MDB, specifically within these five LGAs, as it measures a region's exposure to drought as a hazard, and its vulnerability to extended periods of water shortage (Yin et al. 2014).

The importance of developing a unique drought risk index, specific to the area of investigation, when assessing agricultural drought risk on local community scales, has been emphasised in earlier studies (Wilhelmi and Wilhite 2002; Raikes et al. 2019). A recent study by Rahmati et al. (2020) developed a drought risk index to map drought risk in a drought-stricken region of $123,897 \mathrm{~km}^{2}$ in South-East Queensland. Although the study region of Rahmati et al. (2020) included areas within the Northern MDB, drought risk in these areas was investigated together with other areas in South-East Queensland on a regional level. There has been no previous research on tailoring a drought risk index for drought risk mapping on a LGA level within the Northern MDB.

Crase et al. (2005) highlights previous assessments of drought risk in the Northern MDB have only considered the socio-economic impacts of drought. A more holistic drought risk assessment using a region-specific drought index, constructed from hazard, vulnerability, and exposure indicators tailored to the features of the Northern MDB, is needed to accurately indicate the current level of drought risk in the selected LGAs. Assessing the extent of drought risk is crucial to determining ADM suitability in Northern MDB LGAs (Adeyinka et al. 2016). The development of a region-specific drought risk index and the accurate assessment of drought risk extent in each LGA will allow decision-makers to observe where ADM resources are being appropriately allocated, and identify areas that require increased attention and provision of additional resources to enhance ADM resilience (Sena et al. 2017).

In this study, we assessed the current ADMSs implemented within the Northern MDB, and determined the extent of proactivity, effectiveness, and suitability of these strategies in the context of the key drought-affected areas. This assessment allowed us to examine the 
potential effectiveness of a user-centred I-EWS for drought to improve ADMSs in Northern MDB farming communities.

The paper is organised as follows. Data and methodology used for assessment of drought hazard, vulnerability, and exposure in five selected agricultural regions of the Northern MDB are presented in Sect. 2. Results of calculations of drought risk index and assessment of the proactivity, effectiveness, and suitability of three major ADMSs used in the Northern MDB are presented in Sect. 3. The results are discussed in Sect. 4, and conclusions are presented in Sect. 5.

\section{Data and methods}

\subsection{Selection of hazard, vulnerability, and exposure indicators used for drought risk assessment in the Northern MDB}

Developing a region-specific drought risk index is the key to accurate drought risk mapping; effective drought risk indicators must be tailored to measuring agricultural drought specifically in the Northern MDB. The development of a region-specific drought risk index ensures that once the extent of proactivity and effectiveness of ADMSs is determined, suitability can be investigated by observing whether the most proactive and effective strategies are being used in the most at-risk agricultural areas (Santos et al. 2014).

Hazard, vulnerability, and exposure indicators most applicable to drought risk assessment in five selected LGAs were determined by integrating information regarding the characteristics of the Northern MDB and analysis of similar approaches to indicator selection used in earlier studies. The selected hazard, vulnerability, and exposure indicators contributed to the assessment of the potential happening of a drought event causing adverse effects for sectors within the Northern MDB (hazard), the impact which a drought event may have on aspects of Northern MDB communities (vulnerability), and the assets and the elements in the Northern MDB that are exposed to potential losses caused by adverse drought effects (exposure).

The climatic and socio-economic characteristics of the Northern MDB were used to infer whether indicators used in earlier studies would be suitable for use in the current study. Specifically, the sub-tropical/grassland climate [Köppen classification system (Bureau of Meteorology 2014)] and diverse geography of the Northern MDB was considered, as well as small community sizes, stable socio-economic features, and the prevalent land use types of grazing, dryland cropping and irrigated cropping [Australian Bureau of Statistics (ABS) 2017].

Indicators used in earlier studies were analysed in terms of efficiency and usability (Table 1). The WMO Handbook of Drought Indicators and Indices (Svoboda and Fuchs 2016) was used to determine the extent of hazard indicator feasibility and relevance. Only hazard indicators that had been recommended by the WMO were used in this study. The practicality and efficiency of vulnerability and exposure indicators, not listed by WMO, was investigated through observing use in earlier studies.

In this study, the Standardised Precipitation Index (SPI) and the Vegetation Health Index (VHI) were determined to be appropriate indicators for use in measuring drought hazard extent in the Northern MDB LGAs. SPI has been used in a similar drought assessment conducted in Iran, which has similar climatic characteristics to the Northern MDB (Nasrollahi et al. 2018), as well as in other past drought assessments throughout the world 
Table 1 Hazard, vulnerability, and exposure index levels for each of the five LGAs investigated (Paroo Shire, Murweh Shire, Balonne Shire, Maranoa Region and Goondiwindi Region) for 2017, 2018, 2019 and 2020 (from Jan to Dec in 2017, 2018, and 2019 and from Jan to Jul in 2020)

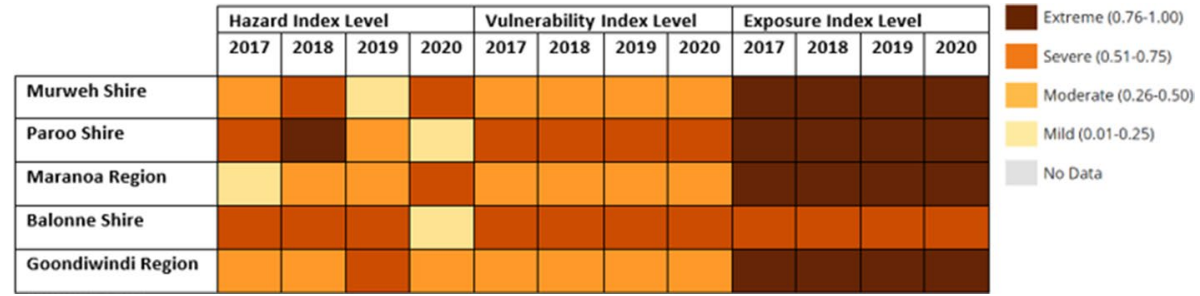

Index level is shown on a $0-1$ orange colour scale, spanning from pale orange [Mild $(0.01-0.25)$ ], to deep orange/brown [Extreme (0.76-1.00)]

(Fallon et al. 2019; Nagarajan and Ganapuram 2015). Additionally, SPI has been given the 'green' light by the WMO (Svoboda and Fuchs 2016) and is suggested as a starting point for monitoring drought hazard.

SPI has been criticised as an indicator of drought hazard as it is derived from a time series based on the difference of precipitation from the mean for a specified time divided by the standard deviation, with both the mean and standard deviation derived from the climatological record (Uddameri et al. 2019). As precipitation probabilities are changing in the face of increasing climate change, the accuracy of SPI in the future for indicating drought hazard is unknown. To address this concern, a best practice methodology was developed to derive 3-month SPI from satellite precipitation estimates (Chua et al. 2020).

Furthermore, SPI is not the sole drought hazard indicator; VHI is also used. If slight inaccuracy affects either indicator, the other is likely to compensate for this so that the overall drought hazard index is not critically impacted. VHI has been used in a similar study of agricultural drought in Zimbabwe (Frischen et al. 2020). Although the climate of Zimbabwe is dissimilar to that of the Northern MDB, Frischen et al. (2020) similarly investigated agricultural drought risk on specific, local community levels.

Agricultural occupation ( $\%$ of total population $>15$ in labour force) and average household income [mean household income (AUD)] were selected as appropriate indicators for measuring drought vulnerability in the Northern MDB. Nasrollahi et al. (2018) used agricultural occupation to indicate drought vulnerability in Iran. Although Iran has different socio-economic characteristics to the Northern MDB, agricultural occupation was deemed an applicable indicator to the vulnerability mapping of the Northern MDB, due to the reliance on the agricultural industry for employment (Byrnes 2015). Saha et al. (2012) used average household income as a vulnerability indicator for drought risk in local Indian villages in arid areas. Although the socio-economic characteristics of the Northern MDB differ to India, like the study area of Saha et al. (2012), the Northern MDB has limited water availability and restricted employment opportunities. Frischen et al. (2020) also included average household income as an indicator of vulnerability.

Land use (type) and average elevation were selected as appropriate exposure indicators to use in this study. Frischen et al. (2020) similarly computed drought exposure using a land use/land cover dataset differentiating between rainfed and irrigated agriculture. Likewise, land use was used as the main indicator of drought exposure in a comparable drought risk assessment by Dayal et al. (2018) in South-East Queensland. Dayal et al. (2018) also used elevation as an indicator, but for drought vulnerability. Following further research 
into what drought vulnerability and exposure mean (Korada et al. 2018; Van Lanen et al. 2017), it was decided that the reasoning given by Dayal et al. (2018) describes elevation as a drought exposure factor. Additionally, Huang et al. (2014) used elevation as an indicator of drought exposure, as assets on differing elevations experience disparate drought impacts. For example, elevation is positively related to water abstraction difficulty throughout drought periods (Huang et al. 2014).

All selected indicators are defined in "Appendix 2". It is important to note that as this was intended to be a tailored and specific drought risk assessment for the Northern MDB on a localised scale, only a small number of highly valuable and appropriate hazard, vulnerability and exposure indicators were selected and used. If a large assortment of indicators were used for each of the indices, the assessment may have been too general to highlight the variation in drought risk between the local areas under investigation (Pulwarty and Sivakumar 2014). Additionally, data availability was limited so ideal vulnerability and exposure indicators like water consumption, total grazing pressure, commodity prices, debt income ratio, weed infestation, etc. which have been postulated as useful drought risk indicators in earlier studies (e.g., Stafford Smith et al. 2008), could not be considered in this research. Future research could investigate data availability for these indicators in aim of creating databases for these indicators so that they may be selected for use in further drought risk assessment.

\subsection{Data and methods for drought risk assessment}

Data for each of the selected indicators were collected from publicly available sources.

1. Hazard indicators the SPI-from IRI database [International Research Institute for Climate and Society (IRI) 2020]; the VHI-from NOAA database [National Oceanic and Atmospheric Administration (NOAA) 2020]

2. Vulnerability indicators Average Household Income (AUD) and Agricultural Occupation (\% of total population $>15$ in labour force) - from Australian Bureau of Statistics (ABS) [Australian Bureau of Statistics (ABS) 2017]

3. Exposure indicators Elevation (average over LGA area)-from Topographic map of Queensland (Department of Natural Resources Mines and Energy 2020); Land Use (type) - from Queensland Government ArcGIS mapping source (Department of Environment and Science 2019).

Thresholds were applied prior to index calculations and mapping to determine the variance of indicator data between each of the five LGAs. Drought risk thresholds suitable for measuring drought risk in the Northern MDB were adapted from earlier studies to ensure accuracy (Dayal et al. 2018; Frischen et al. 2020; Williges et al. 2017). If no noticeable variance was evident between the five regions for an indicator, that indicator was deemed unsuitable for use in index calculations. All indicators listed above displayed variance and were included in index calculations.

To calculate the vulnerability, exposure, and hazard indices, data were standardised using a fuzzy method in ArcGIS 10.7 [Environmental Systems Research Institute (ESRI) Inc. 2019]. Prior to the performance of the fuzzy function, fuzzy membership classes were assigned to each indicator, describing the relationship between the indicator and drought risk as recommended in Dayal et al. (2018); the two classes of fuzzy membership assigned in this study were fuzzy small and fuzzy large. The fuzzy large (fuzzy small) transformation 
function was used when the larger (smaller) input values were more likely to contribute to drought risk.

Each individual indicator to be included in the drought hazard, vulnerability and exposure index calculations was mapped on ArcGIS $_{10.7}$ for the five LGAs, using original data. The base map used for all map layers, outlining Queensland LGAs, was sourced from Department of Industry Science Energy and Resources (2020). Data was scaled between $0-1$ based on the possibility of the data contributing to drought risk, where 0 was assigned to those values that were definitely not going to contribute, and 1 was assigned to those values that were definitely going to contribute to drought risk. The entire range of possibilities between 0 and 1 were assigned to some level of possible membership (Dayal et al. 2018).

Once the data for each indicator (to be included in calculations) was appropriately standardised, weights were assigned to each indicator and the hazard, vulnerability and exposure indices were calculated using Eqs. (1), (2) and (3), respectively.

$$
\mathrm{HI}=\sum_{i=1}^{n}\left(w_{i} * x_{i}^{\prime}\right),
$$

where HI is the Hazard Index, $n$ is the number of Hazard Indicators, $X_{i}^{\prime}$ refers to the standardised indicators and $W_{i}$ refers to the respective indicator weight.

$$
\mathrm{VI}=\sum_{i=1}^{n}\left(w_{i} * x_{i}^{\prime}\right),
$$

where VI is the Vulnerability Index, $n$ is the number of Vulnerability Indicators, $X_{i}{ }^{\prime}$ refers to the standardised indicators and $W_{i}$ refers to the respective indicator weight.

$$
\mathrm{EI}=\sum_{i=1}^{n}\left(w_{i} * x_{i}^{\prime}\right),
$$

where EI is the Exposure Index, $n$ is the number of Exposure Indicators, $X_{i}^{\prime}$ refers to the standardised indicators and $W_{i}$ refers to the respective indicator weight.

A weighting scheme for the relative hazard, vulnerability, and exposure indicators was developed, based on the relative importance and contribution of each factor for the specific index which it informs. This weighting scheme was developed on a $0-1$ scale, with 0 indicating no probable contribution to the relative index and 1 being total probable contribution to the relative index (Dayal et al. 2018; Frischen et al. 2020). The numerical weightings assigned to each indicator were determined by investigating expert weights provided in earlier studies (see "Appendix 3" for details).

A Hazard Index, Vulnerability Index, and Exposure Index were calculated for 2020 using data available up to July. All indices were calculated for three additional years (2017, 2018, and 2019), and four seasonal periods (spring, summer, autumn, and winter) from 2019-2020, to verify the accuracy of results of the drought risk analysis.

Once the vulnerability, hazard, and exposure indices were calculated, the data were imported to ArcGIS ${ }_{10.7}$. Spatial maps of the area covering the five LGAs, representing vulnerability, exposure, and hazard per unit area were produced. The final drought risk index for each of the five LGAs was determined through the integration of the drought vulnerability, hazard, and exposure index maps using the Fuzzy Gamma Overlay (with a gamma value of 0.9) function in ArcGIS ${ }_{10.7}$. Refer to "Appendix 4" for mathematical equations of the Fuzzy Gamma Overlay function. The optimal final drought risk map for each LGA 
was then generated in ArcGIS $_{10.7}$. The extent of drought vulnerability, hazard, exposure, and risk displayed on the respective maps was classified into four levels: mild, moderate, severe, and extreme. These classifications are commonly used in drought risk assessments (Dayal et al. 2018; Frischen et al. 2020).

The final drought risk maps were validated through spatially correlating seasonal hazard maps (spring 2019, summer 2019/2020, autumn 2020 and winter 2020) and seasonal drought risk maps (spring 2019, summer 2019/2020, autumn 2020 and winter 2020) with Space-based Weather and Climate Extremes Monitoring (SWCEM) soil moisture data [Soil Moisture Operational Product System (SMOPS) Season Average], adapting an approach used in an earlier study (Dayal et al. 2018). Soil moisture data were gathered from the National Oceanic and Atmospheric Administration (NOAA) for the spring and summer periods of 2019, and autumn and winter periods of 2020. Seasonal soil moisture is an appropriate factor for validating drought hazard and risk as it is indicative of agricultural drought as it has been proven to be directly related to drought stress on crops (Svoboda and Fuchs 2016).

The validation was conducted in ArcGIS $_{10.7}$ using the spatial analyst tool band collection. This tool provides statistics for the multivariate analysis of a set of raster bands, outputting the minimum, maximum, mean, and standard deviation for each raster band analysed, and a correlation matrix depicting the correlation between raster bands.

\subsection{Data and methods for ADMSs}

Stakeholder surveys were designed using a Criteria-Based Ranking (CBR) method which uses collaborative stakeholder engagement to develop ranks (Ho 2018). The CBR methodology, previously used by Ho (2018) to rank different environmental indicators, was adapted to suit the ranking of different ADMSs.

The three strategies under assessment (the MDB Plan, Water Trading, and Government Assistance) were ranked by each participant through responding to a series of proactivity and effectiveness criteria statements. Criteria statements were developed through analysis of relevant earlier studies (Cobon et al. 2009; Dayal et al. 2018; Williges et al. 2017). A response scale was also developed using best practices expressed in the literature (Ho 2018). Criteria statements were weighted equally since the earlier study by Ho (2018) concluded that applying weights to individual criteria statements did not significantly change ranking results. However, since each context in which CBR is used is different, future studies may consider consulting with key stakeholders, as to whether the unequal weighting of criteria statements is required.

Participants from three key stakeholder groups (local farming individuals, Queensland Government officials, and local farming association individuals) were contacted through public domain sources and personal networks via email and phone. Each participant was given an Explanatory statement and Consent Form, as per ethics, prior to completing the survey. Surveys were conducted in June-July 2020.

The survey was conducted using the Qualtrics platform. Participants were asked to rank proactivity and effectiveness criteria statements on a scale of 1-5 (1-strongly disagree, 2-somewhat disagree, 3-neither disagree nor agree, 4-somewhat agree, 5-strongly agree), for each of the three ADMSs. There were 11 total criteria statements for proactivity and 12 for effectiveness. Each of the participant's statement rankings were summed to get overall effectiveness and proactivity statement ranks for each strategy. All 11 overall statement ranks were added to generate the final proactivity rank for each strategy, and all 12 
overall statement ranks were added to obtain the final effectiveness rank for each strategy. To increase the value of ranking results, the statistical significance [likelihood that two variables are related due to a factor other than chance (Zhang et al. 2011)] of the relationship between ADMS and proactivity rankings was analysed.

The relationship between the proactivity rankings/effectiveness rankings and ADMS type was examined with an ANOVA. A student's $t$-test was used to determine the significance of the difference between the means of each ADMS ranking, until each ADMS rank had been compared to each of the other ADMS rankings. $T$-test assumptions were checked by plotting the data distribution on boxplots. ANOVA assumptions were checked by plotting data, and by assuring experimental data was independent. All assumptions were met, thus the aforementioned tests proceeded. All statistical tests used $\alpha=0.05$.

\section{Results}

\subsection{Drought risk assessment}

Results from the 2020 drought risk index and mapping displayed high drought risk for all five LGAs with varying levels of hazard, vulnerability, and exposure. These results have been validated through comparison with three past years $(2017,2018$, and 2019) and seasonal correlation with SWCEM soil moisture data (SMOPS Season Average).

Agricultural occupation, average household income, elevation, SPI, VHI and land use all displayed variation between data collected for each of the LGAs. These indicators were included in the index calculations. Index values for the vulnerability, exposure and hazard indices displayed varying degrees of drought vulnerability, exposure, and hazard for each of the five LGAs. Drought hazard, vulnerability and exposure maps displayed the calculated index values, computed from each standardised indicator value (for summary see Table 1).

Current (2020) drought hazard was shown as considerable for three of the five LGAs (Table 1). The Maranoa Region and Murweh Shire were determined to have a severe drought hazard (with standardised hazard index values between 0.51 and 0.75 ), and the Goondiwindi Region was displayed as having moderate drought hazard (with standardised hazard index value between 0.26 and 0.50). Paroo Shire and Balonne Shire displayed a lesser degree of drought hazard, exhibiting a mild level of hazard (with standardised index values between 0.01 and 0.25 ).

All LGAs exhibited a high degree of current (2020) drought vulnerability (Table 1). The Maranoa Region, the Goondiwindi Region and Murweh Shire displayed moderate levels of drought vulnerability, while Paroo Shire and Balonne Shire were shown to have severe drought vulnerability.

As with drought vulnerability, all LGAs demonstrated extensive levels of current (2020) drought exposure (Table 1). The exposure maps indicated that all LGAs except Balonne Shire had an extreme level of drought exposure (with exposure index values ranging from 0.76 to 1). Balonne Shire was shown to have a severe level of drought exposure.

As a result, the overall current (2020) drought risk map (overlay of vulnerability, hazard, and exposure maps) marked each of the five LGAs to have very high levels of drought risk (Fig. 3). Paroo Shire and Balonne Shire exhibited a lower level of drought risk compared to all other LGAs. The Goondiwindi Region, Maranoa Region and Murweh Shire all 

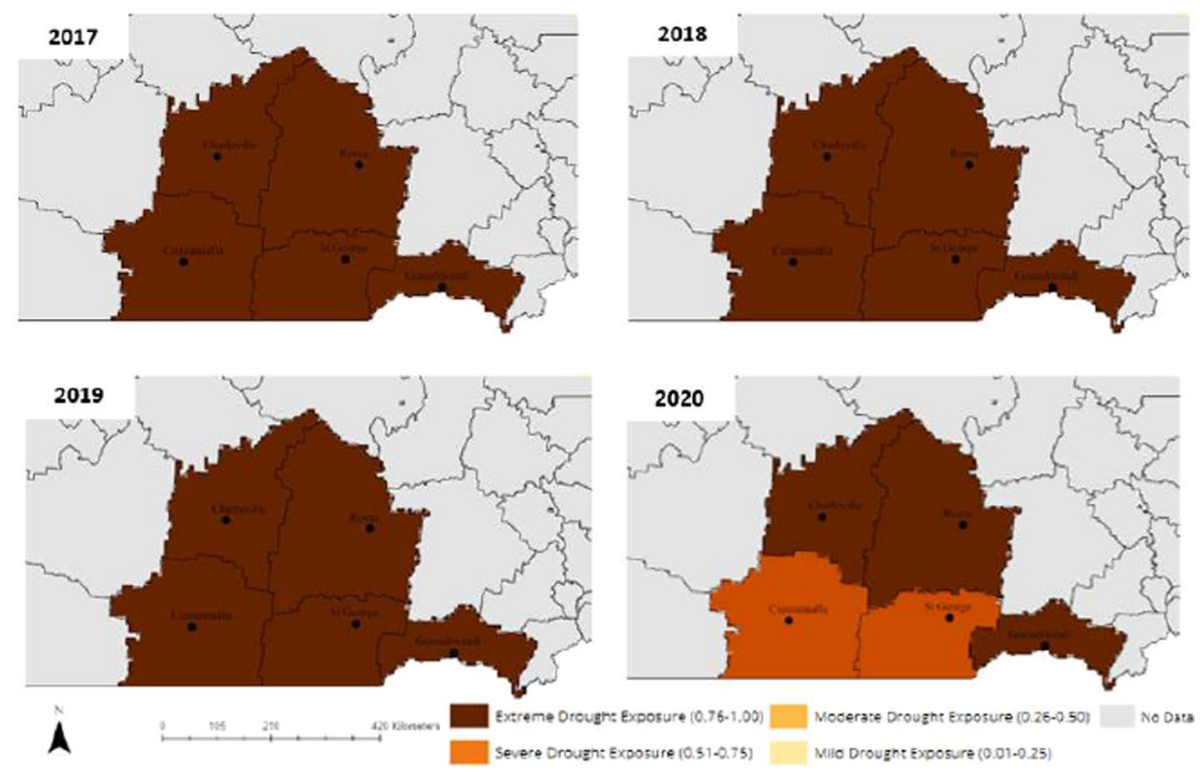

Fig. 3 Drought risk maps for 2017, 2018, 2019, and 2020 (from Jan to Dec in 2017, 2018 and 2019 and from Jan to Jul in 2020) indicating drought risk on an LGA level, in Paroo Shire [Regional Hub (RH) Cunnamulla], Murweh Shire (RH Charleville), Balonne Shire (RH St George), Maranoa Region (RH Roma) and Goondiwindi Region (RH Goondiwindi). Drought risk extent is shown on a 0-1 orange colour scale, spanning from pale orange [Little Risk $(\leq 0.25)$ ] to deep orange/brown [Extreme Risk $(\leq 1.0)$ ]

displayed an extreme level of drought risk, whereas Paroo Shire and Balonne Shire were shown to have a severe extent of drought risk.

The current (2020) drought risk level was corroborated with drought risk trends calculated and displayed for each of the five LGAs for the past three years $(2017,2018$, and 2019). Similar to the 2020 drought risk results, a very high drought risk level (extreme) was seen for all five LGAs throughout the past three years (Fig. 3).

The yearly drought risk maps were further validated through correlating a set of seasonal hazard maps (spring 2019, summer 2019/2020, autumn 2020 and winter 2020) and seasonal drought risk maps (spring 2019, summer 2019/2020, autumn 2020 and winter 2020) (summary of seasonal maps provided in Table 2) with SWCEM soil moisture data (SMOPS season average). There was an evident correlation between seasonal soil moisture and the seasonal hazard maps, as well as an evident correlation between seasonal soil moisture and the seasonal drought risk maps produced (Table 3).

\subsection{Assessment of drought impacts management using current ADMSs}

A search of the relevant literature expressed the main type of ADMS used in each LGA (out of the major three strategies assessed: MDB Plan, Water Trading, and Government Assistance). Three sources discussing the current (2015-2020) ADMSs used in each LGA were analysed to determine which strategy was mentioned the most. A total of 15 (three for each LGA) relevant sources (journal papers and government documents published between 2015 and 2020) were analysed. The specific strategy that was mentioned the most in the set 
Table 2 Hazard, vulnerability, exposure, and risk index levels for each of the five LGAs investigated (Paroo Shire, Murweh Shire, Balonne Shire, Maranoa Region and Goondiwindi Region) for the seasonal periods in the past year (from Spring 2019 to Winter 2020)

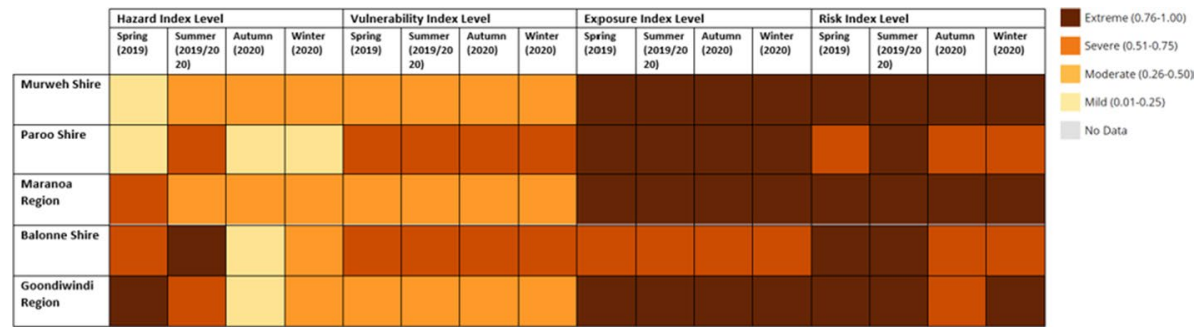

Index level is shown on a $0-1$ orange colour scale, spanning from pale orange [Mild $(0.01-0.25)$ ], to deep orange/brown [Extreme (0.76-1.00)]

of sources analysed for each LGA was assumed to be the main ADMS used in that region. To examine the suitability of ADM, the final effectiveness rank for the main ADMS found to be used in each LGA was cross-referenced with the optimal drought risk map to determine if the most effective ADMS was implemented in the most at-risk LGAs.

\subsubsection{Proactivity ranking for Northern MDB ADMS}

To increase the value of proactivity ranking results, the statistical significance [likelihood that two variables are related due to a factor other than chance (Zhang et al. 2011)] of the relationship between ADMS and proactivity rankings was analysed.

There was a statistically significant relationship found between ADMS type and proactivity statement rankings $\left(F_{2}=15.49, p=<0.0001\right)$. The MDB plan proactivity statement rankings were statistically lower than those of Water Trading $\left(t_{18}=-2.20, p=0.04\right)$ and Government Assistance $\left(t_{18}=-4.81, p=0.0001\right)$. Additionally, there was a statistically significant difference found between Water Trading and Government Assistance rankings, with Water Trading ranked lower than Government Assistance $\left(t_{15}=-3.56, p=0.003\right)$.

It was found that all three Northern MDB ADMS's proactivity ranks were not optimal.

The total rank formed from the summation of the statement rankings indicated that Government Assistance was overall ranked the most proactive (score of 449). This rank was much greater than both Water Trading (score of 382) and the MDB Plan, which was ranked as the least proactive strategy (score of 350).

\subsubsection{Effectiveness ranking for Northern MDB ADMS}

To increase the value of effectiveness ranking results, the statistical significance of the relationship between ADMS and effectiveness rankings was analysed.

There was a statistically significant relationship found between ADMS type and effectiveness statement rankings $\left(F_{2}=25.83, p=<0.0001\right)$. Both the MDB plan $\left(t_{21}=-6.39\right.$, $p=<0.0001)$ and Water Trading $\left(t_{22}=-5.72, p=<0.0001\right)$ effectiveness statement rankings were statistically lower to those of Government Assistance. However, there was no statistically significant difference evident between the effectiveness statement rankings of the MDB Plan and Water Trading $\left(t_{22}=-0.57, p=0.57\right)$.

It was found that effectiveness rankings were suboptimal for all of the major Northern MDB ADMS's. 


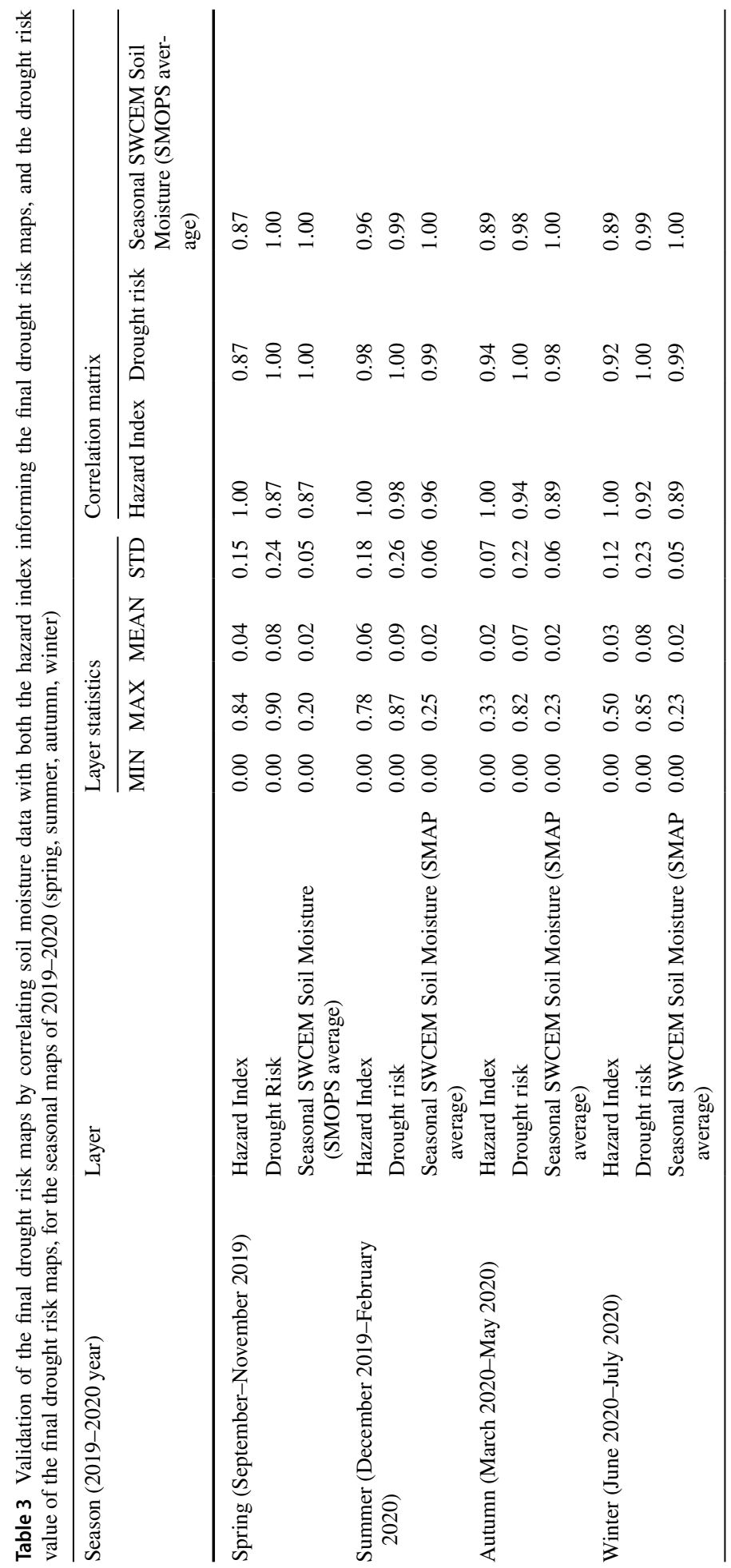


The total rank calculated from the summation of the effectiveness statements indicated that Government Assistance was overall ranked the most effective (score of 540), as it was for proactivity. This rank was distinctly larger than both the rank of Water Trading (score of 409) and the MDB Plan (score of 397). As there was no significant difference between the effectiveness rank of the MDB Plan and that of Water Trading, it cannot be said that the MDB Plan was ranked differently to Water Trading.

\subsubsection{Suitability assessment of existing ADMSs used in the Northern MDB}

It was found that Government Assistance was the main ADMS mentioned in the literature regarding ADM for Paroo Shire, the Maranoa Region and Murweh Shire (Byrnes 2015). The MDB Plan was the main strategy found listed in the literature discussing ADM in the Goondiwindi Region (Goondiwindi Regional Council 2020). Water Trading was the major strategy found in the literature covering ADM for Balonne Shire (Marsh 2018). The results of the literature search, combined with the main land use type (found when collecting data for the drought exposure index), effectiveness rankings, and the final drought risk map, indicate the extent of current ADM suitability in each LGA (Table 4).

LGAs displayed varying levels of ADMS suitability. ADM was found to be 'not suitable' in the Goondiwindi Region as the main ADM used had the lowest (tied) effectiveness ranking and an extreme level of drought risk. Balonne Shire displayed a severe level of drought risk but used a low ranking ADMS. However, as the major land use type of the region is less exposed to drought than that of the other LGAs and the fact that Balonne Shire did not display an extreme level of drought risk like the Goondiwindi Region, Maranoa Region and Murweh Shire, it is concluded that ADM in Balonne Shire has a slight level of ADM suitability. ADM was mostly suitable in Paroo Shire as it uses the most effective ADMS; however, as it is of lower risk to drought compared to the other LGAs, resources could be better used elsewhere. The Maranoa Region and Murweh Shire were indicated to have very suitable ADM as they were of extreme risk to drought and implemented the most effective ADMS.

\section{Discussion}

Investigating prospects for a user-centred I-EWS to increase the efficiency of ADM in the Northern MDB, this study assessed three major ADMSs implemented within five LGAs of the Northern MDB and determined the extent of proactivity, effectiveness, and suitability of these strategies. A region-specific drought risk index tailored to evaluating drought in the Northern MDB has been developed and the index data integrated with proactivity and effectiveness rankings of ADMSs to determine management suitability.

Results of the current (2020) drought risk assessment, management rankings and current suitability of ADMSs in five LGAs in the Northern MDB are discussed in the following sections.

\subsection{Drought risk}

Current (2020) drought risk was high for all five LGAs due to the climatic, socio-economic, and geographic characteristics of each area. Summary of discussion on risk assessment results for 2020 is given in Table 5 . 


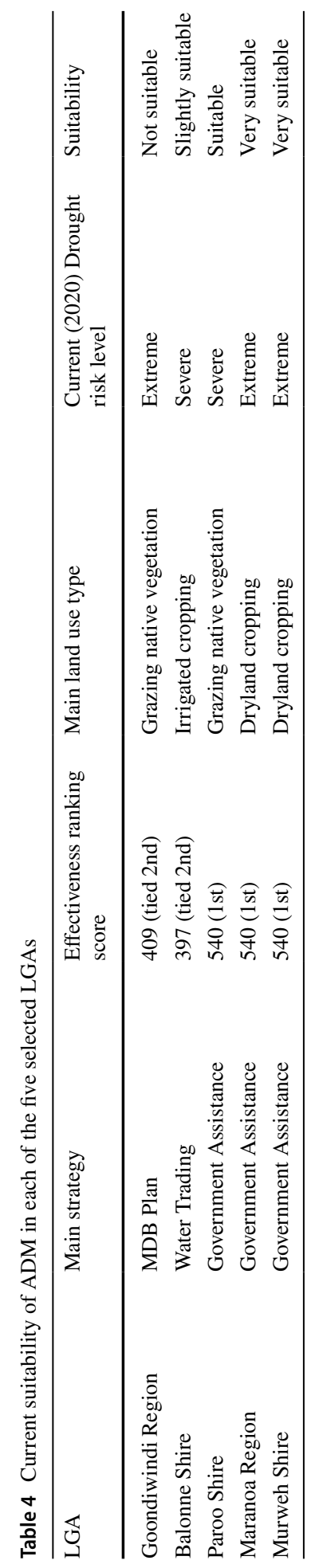




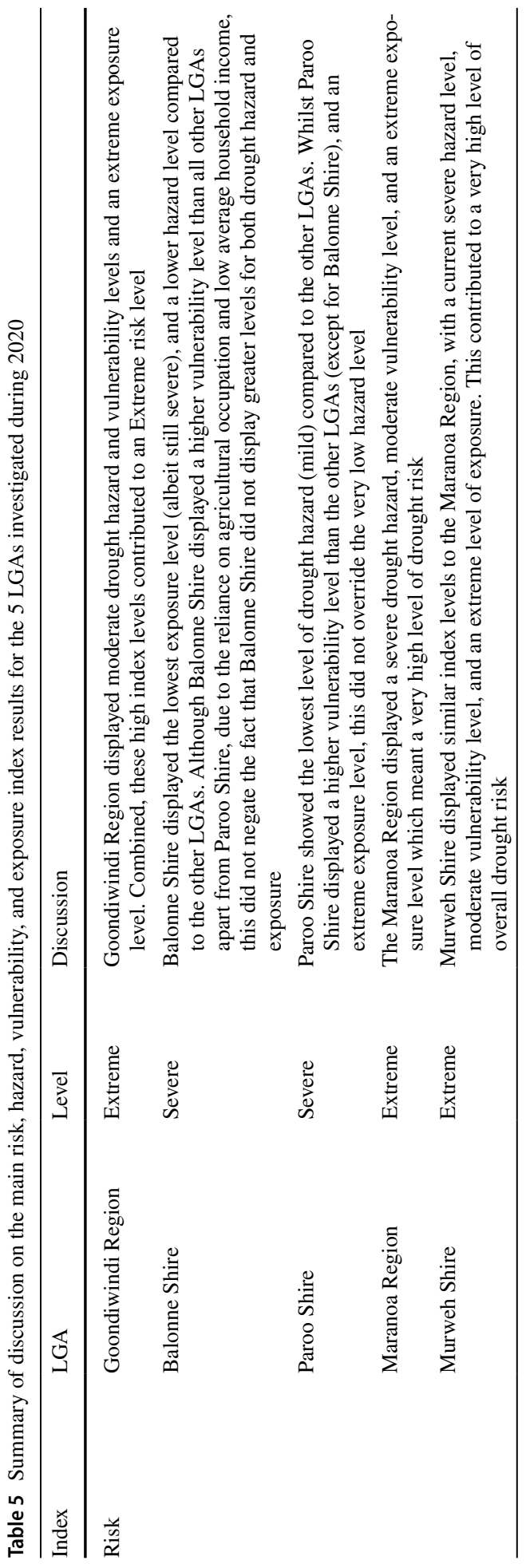




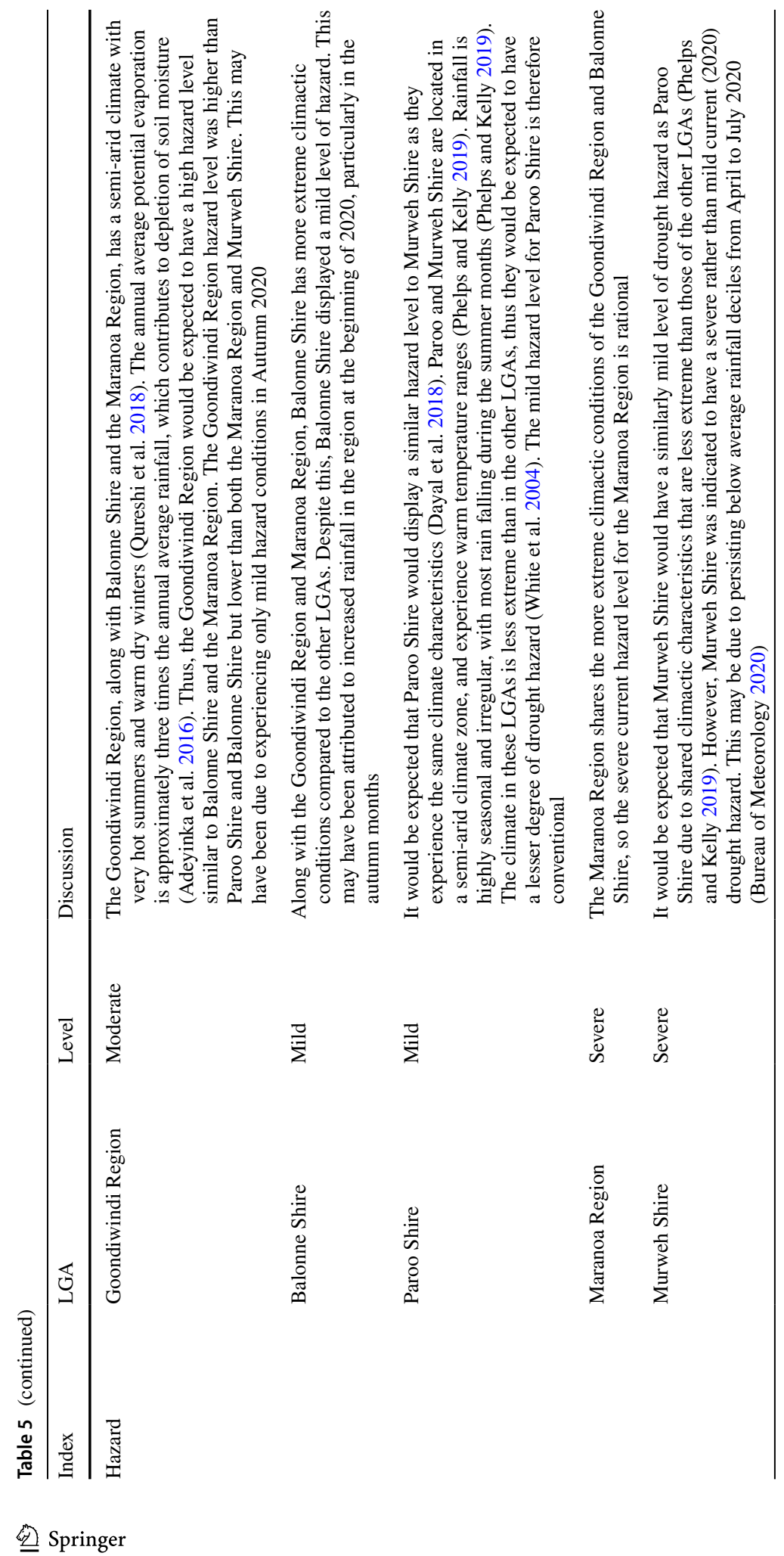




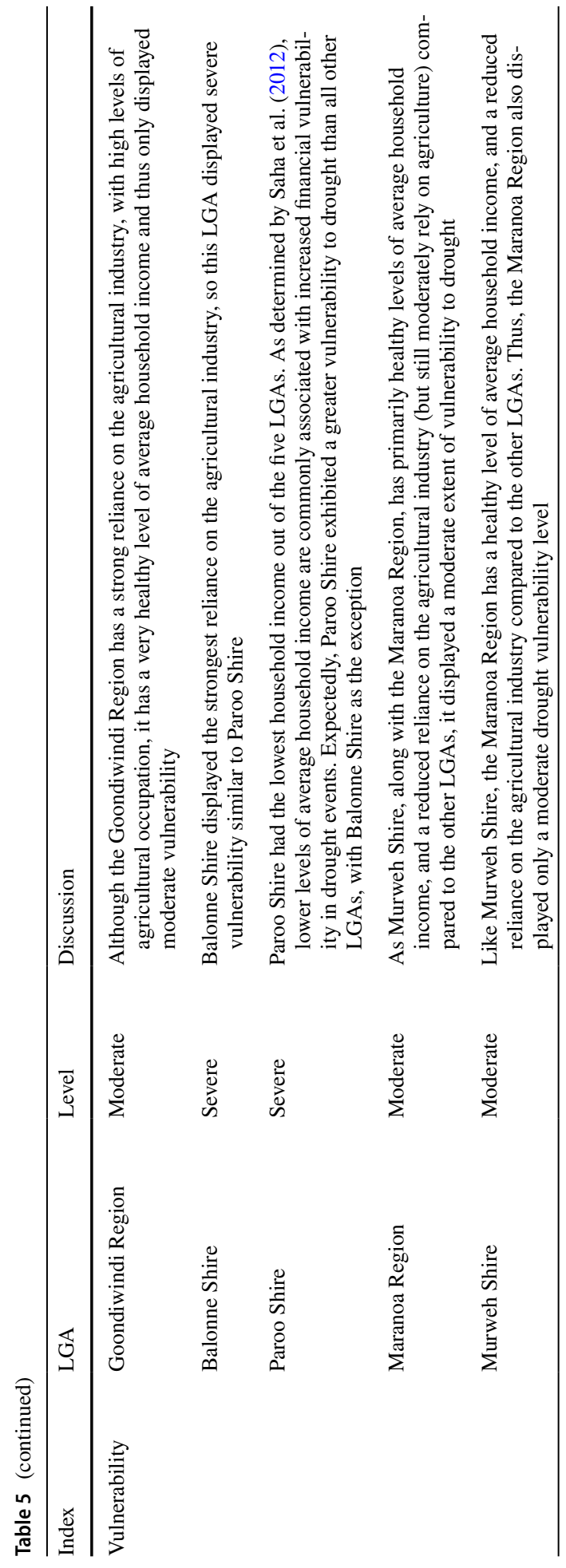




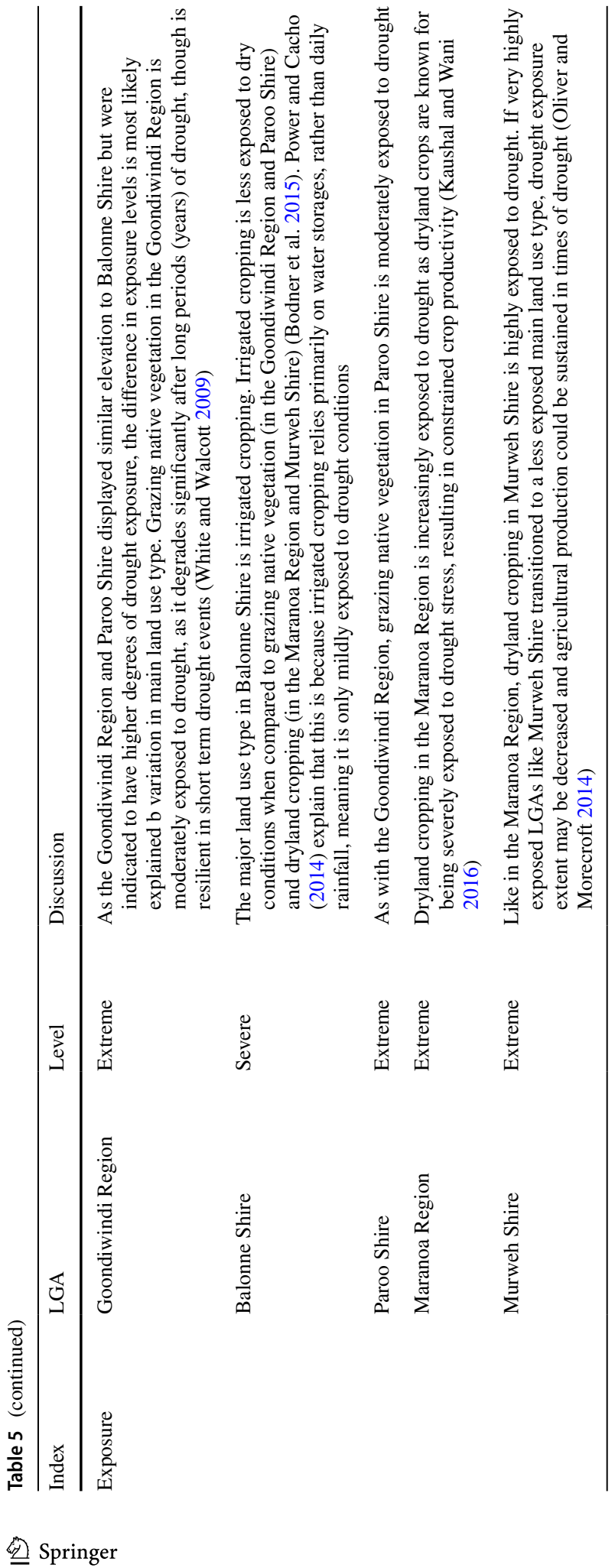




\subsection{Management rankings}

Proactivity and effectiveness of three main ADMs-Government Assistance, MDB Plan and Water Trading - were evaluated. Proactive ADM prepares for drought as a risk, rather than responding to drought as a crisis (Abel et al. 2016). In this study, ADM in the selected LGAs was deemed sufficiently proactive if the major ADMS used emphasises collaborative stakeholder preparedness and incorporates early warning information. ADMSs in the chosen LGAs were deemed effective if they displayed a high quality of stakeholder communication and collaboration and allowed for the independent implementation of ADM by local farming communities (Otkin et al. 2015).

It was found that proactivity rankings were consistently lower than effectiveness rankings. It is speculated that this is due to the universally common practice of striving for high management efficiency whilst also managing drought as a crisis during or after an event has occurred, rather than managing it as a risk prior to an event reaching an emergency level (Paneque 2015). Proactivity rankings for the MDB Plan were significantly lower than those of Water Trading and Government Assistance. Government Assistance was also ranked significantly higher than Water Trading. This was an unexpected result, as the MDB Plan is expressed in the literature as the major ADMS used in the Northern MDB, thus it was assumed it would be the most proactive (Connell and Grafton 2011; Kiem 2013; Wheeler et al. 2014).

This unexpected result may be due to the strong limitations constraining the proactivity of the MDB Plan. In an examination of water reform in the MDB, Connell and Grafton (2011) suggest that there is a gap between state-level implementation of the MDB Plan and an apparent lack of public understanding of the plan's objectives. Additionally, the MDB Plan is only reviewed every 10 years, which limits the amount of adaptation that it can have to changing drought frequency and intensity that may occur over the years (Quiggin et al. 2010). Under climate change, rapid increase in frequency of drought events is expected, thus 10 years may be too large of a time interval (Hart 2016). Results of this research suggest that review of the MDB Plan be preferably conducted more frequently and consider feedback from local farming individuals.

Government Assistance was ranked significantly higher than the MDB Plan and Water Trading. We speculate that whilst the MDB Plan and Water Trading consider the needs of the Northern MDB as a whole (Docker and Robinson 2014), Government Assistance considers the needs of individual local farmers and adapts to the ever-changing nature of drought events in the Northern MDB, albeit slowly. However, the effectiveness ranking for Government Assistance was not optimal.

Earlier studies, like the analysis of governmental risk management approaches in the MDB by Pittock and Connell (2010), show that Government Assistance is restricted by certain limitations. Historically, financial assistance programs offered by the Queensland government have specific criteria for participation, generalised for farmers throughout the entire MDB (Kiem 2013; Pittock and Connell 2010). Furthermore, it was noted by Abel et al. (2016) in their investigation of management strategies in the MDB to form criteria for the arrangement of risk adaptation actions, that the effectiveness of Government Assistance is challenged by the fact that it encourages focus on government intervention rather than on effective self-management, resilience, and sustainability in local farming communities. Consequently, local farmers are not equipped and supported to manage the adverse impacts of drought independently, thus inhibiting the effectiveness of ADM. 
Overall, proactivity was exhibited as low for all three ADMSs, with Government Assistance ranked as the most proactive and effective.

\subsection{Management suitability}

Suitable ADM is location-specific and incorporates effective collaboration between key stakeholders, to ensure that ADMSs can be independently implemented and managed in high-risk farming communities (Nguyen-Huy et al. 2020). In this study, ADM is deemed highly suitable if effective ADMSs are used in high-risk LGAs, with largely droughtexposed main land use types, as such regions require resilient ADM and prioritised drought resource allocation.

Government Assistance is the most used ADMS for Paroo Shire, the Maranoa Region and Murweh Shire (Byrnes 2015). Whereas the MDB Plan is mainly used in the Goondiwindi Region (Goondiwindi Regional Council 2020). Balonne Shire principally relies on Water Trading, compared to the other two ADMSs (Marsh 2018).

The Maranoa Region and Murweh Shire were found to implement very suitable ADM, as the most effective ADMS (Government Assistance) is used in these LGAs that are extremely at risk, where the main land use type (dryland cropping) is severely exposed to drought (Kaushal and Wani 2016). In comparison, ADM in the Goondiwindi Region was deemed to be not suitable. This was attributed to the fact that one of the least effective ADMS's (MDB Plan) is used in this extremely at-risk LGA, where the main land use type (grazing native vegetation) is moderately drought exposed. In the Goondiwindi Region, ADM could be improved with the increased focus on Government Assistance rather than the MDB Plan.

ADM was found to be only slightly suitable in Balonne Shire. This was due to the major use of one of the least effective ADMS's (Water Trading) in this severely at-risk LGA (Docker and Robinson 2014). However, because the major land use type (irrigated cropping) is only mildly exposed to drought, it is understandable as to why the most effective ADMS is not used. Alternatively, ADM in Paroo Shire was observed to be suitable. The most effective ADMS (Government Assistance) is used in this severely at-risk LGA, where a moderately drought exposed land use type is common (grazing native vegetation). However, it is not found to be 'very suitable' like Murweh Shire and the Maranoa Region, as ADM resources may be better prioritised elsewhere where drought risk is extreme, and management is poor (Paneque 2015).

In summary, ADM in the Maranoa Region and Murweh Shire was found to be very suitable, ADM in Paroo Shire was found to be suitable, with ADM in Balonne Shire and the Goondiwindi Region requiring review and further improvement.

\subsection{Priority Areas for ADM review}

The two LGAs that are of high priority for ADM review include the Goondiwindi Region and Balonne Shire. This study highlights the importance to prioritise a review of ADM in Balonne Shire and the Goondiwindi Region as these LGAs are at a very high risk to drought (severe risk and extreme risk respectively) and rely on unsuitable ADMSs that lack proactivity.

Paroo Shire is of low priority for review as it mainly uses the most effective ADMS to counter the severe drought risk threatening the moderately exposed main land use type of grazing native vegetation. Similarly, the Maranoa Region and Murweh Shire are of low 
priority when considering reviewing ADM, as the major ADMS used in both LGAs (Government Assistance) is sufficiently proactive and very suitable to combat the extreme risk which drought poses to these areas.

Therefore, future investigation should predominantly focus on the high priority LGAs of Balonne Shire and the Goondiwindi Region but should still consider Paroo Shire and both the Maranoa Region and Murweh Shire following this. Additionally, the Maranoa Region and Murweh Shire are still at an extreme risk to drought and may require increasingly improved ADM under the possibly intense effects of future climate change. In a comparable study analysing management of water shortage impacts on irrigated agricultural processes, Qureshi et al. (2018) similarly found that local areas in the MDB that are at-risk to water shortages require improved management strategies to sustain agricultural processes, especially when faced with future climate change.

\subsection{Study limitations and way to move forward}

The onset of COVID-19 at the beginning of the study period meant that travel was restricted so local farming individuals could not be spoken to face-to-face. The survey to assess ADMSs was conducted online; more detailed responses may have been obtained if an in-person survey or interview was conducted. Thus, the survey methodology was not optimally comprehensive. Confidence in the study design and results would have been solidified if stakeholders had completed a preliminary survey to gauge what was viewed as the main ADMS in each LGA. This would have made the main survey increasingly targeted towards decision-makers involved in Northern MDB ADM. Furthermore, a validation of the desktop research results should have been performed to confirm result reliability. In-person discussions with stakeholders would have been ideal to validate results, as demonstrated by Ho (2018). However, the prohibition of face-to-face interactions with stakeholders made it difficult to comprehensively conduct a validation of results in this way. As this is a detailed pilot study, the value of findings is unlikely to be affected by these limitations. In the future, further research will be conducted to strengthen findings and confirm methodology accuracy.

A key process to moving forward with improving ADM in high priority and drought risk areas is the development of a user-centred EWS for drought (Kuleshov et al. 2020). Recent studies on designing an I-EWS for drought in the Northern MDB demonstrated the benefits of such system for ADM in these LGAs (Asghari et al. 2021; Bhardwaj et al. 2021); results of those studies suggest that communities can have increased drought resilience when a user-centred EWS for drought is used as part of an ADMS in priority and at-risk areas.

Within the Northern MDB, ADM continues to place an emphasis on crisis management, with local farming communities generally moving from one drought event to another with little, if any, reduction in adverse impacts (Raikes et al. 2019). A user-centred I-EWS actively engages communities involved in preparedness and promotes resilience to drought (Raikes et al. 2019). Therefore, a user-centred I-EWS that is communicated efficiently from the state government level to local farming community level, focused on user needs, would allow for the improvement of ADMS proactivity and suitability in priority and atrisk areas.

A key challenge to the implementation of a user-centred I-EWS for drought in Australia is the poor collaboration and communication between ADM stakeholders (Raikes et al. 2019). Universally, successful user-centred EWSs focus on multi-sectoral and 
interdisciplinary collaboration among stakeholders at each stage in the warning process (monitoring-response-evaluation) (Otkin et al. 2015). Therefore, it is recommended that the potential development of a user-centred I-EWS for drought in the Northern MDB be focused on fostering links between community-based and state-level implementation to maximise benefits.

\section{Conclusions}

A region-specific drought risk index was developed by calculating and integrating drought vulnerability, exposure, and hazard indices, tailored to assessing drought in the Northern MDB. All five of the selected LGAs displayed high levels of drought risk. Paroo Shire and Balonne Shire exhibited a severe extent of drought risk, whilst the remaining LGAs displayed an extreme extent of drought risk. Very high levels of drought risk were expected as each LGA had climatic, socio-economic, geographic and land use attributes which are commonly linked with high levels of drought hazard, vulnerability, and exposure.

Resilient ADMSs are critical for LGA farming communities to sufficiently manage negative drought impacts. Of the three ADMSs explored, Government Assistance was found to be the most effective and proactive. As this strategy was used in Paroo Shire, the Maranoa Region and Murweh Shire, these LGAs were shown to have the greatest ADM proactivity and suitability. The remaining LGAs displayed lesser levels of ADM proactivity and suitability, and thus were shown to be of highest priority for improved ADM.

It is recommended for Balonne Shire and the Goondiwindi Region to undergo further assessment of ADM. The Goondiwindi Region and Balonne Shire could consider supplementary investigation into the proactivity, suitability, and efficiency of current ADMSs, and determine whether the transition to more proactive and suitable ADM is possible. Further assessment could consider the use of a drought EWS, as a user-centred I-EWS can improve the resilience of ADM.

To maximise benefits of an EWS, productive communication and functional links between local farming individuals and state government officials are required. The role of local council officials in ADM could be further explored as they could potentially be the key to creating and sustaining these links. If implemented correctly, a user-centred I-EWS for drought has the potential to increase the drought resilience of farming communities in Northern MDB LGAs. 


\section{Appendix 1}

See Table 6.

Table 6 An analysis of the major limitations of each of the major ADMSs used in the Northern MDB

\begin{tabular}{ll}
\hline ADMS & Major Limitations \\
\hline MDB plan & 1. Lack of coordination and cooperation between stakeholders (Connell and \\
& Grafton 2011) \\
2. Gap between the Queensland government's implementation of the plan, and \\
a lack of public understanding of the plan's objectives in local Northern MDB \\
communities (Connell and Grafton 2011) \\
1. Challenge of accounting for the highly variable nature of water use in different \\
Nater trading \\
and Robinson 2014) \\
2. Local farming community's response to drought is confined by government- \\
controlled funding and water allocation (Docker and Robinson 2014) \\
1. Encourages reliance on resources and financial assistance from the government \\
after a drought event has occurred (Kirby et al. 2014) \\
2. Historically, eligibility criteria for financial assistance is generalised over the \\
entire basin area (Kirby et al. 2014)
\end{tabular}




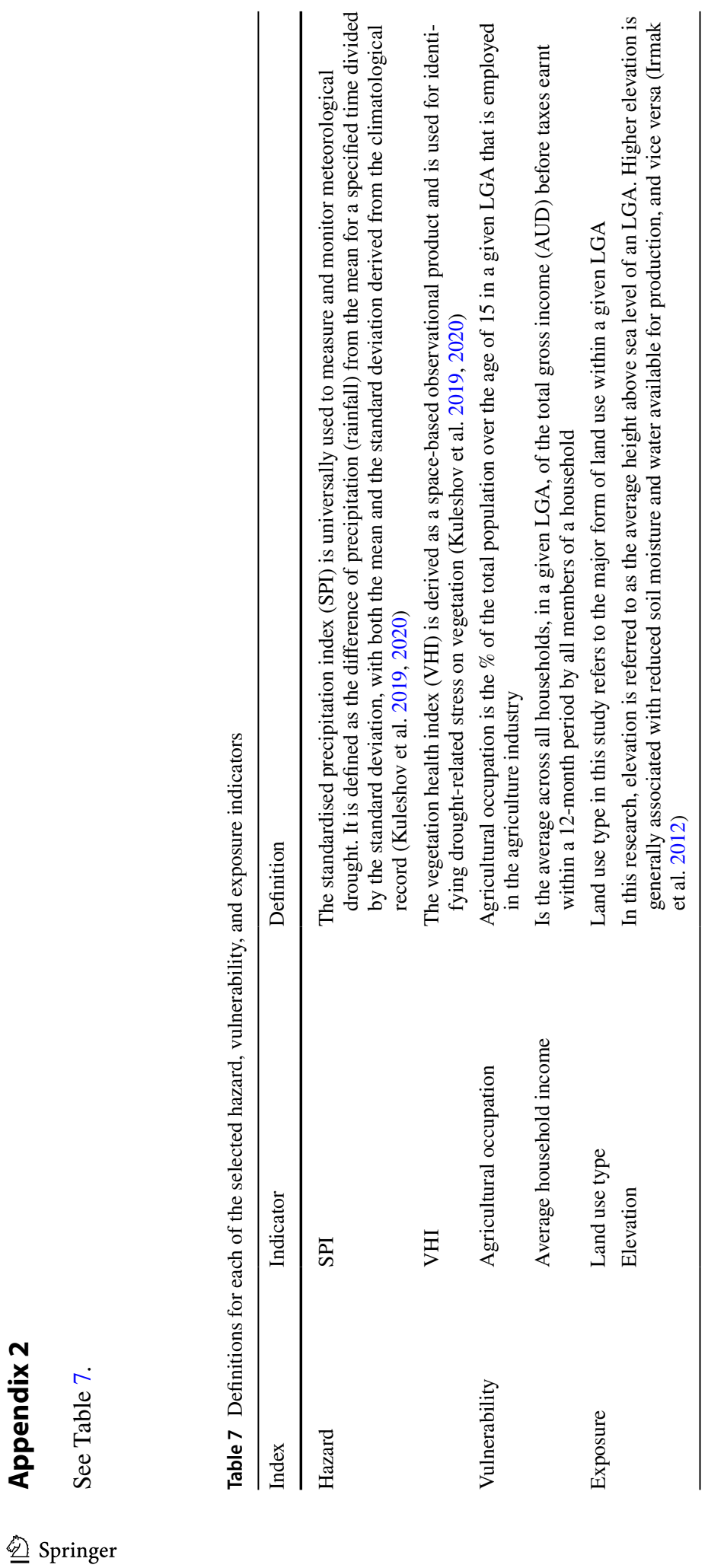




\section{Appendix 3}

See Table 8 .

Table 8 Weights assigned to each indicator informing the hazard index, vulnerability index, and exposure index, on a $0.000-1.000$ scale

\begin{tabular}{llll}
\hline Index & Indicator & Assigned weight & Literature consulted for expert weight \\
\hline Hazard & SPI & 0.500 & Svoboda and Fuchs (2016) \\
Total Index Weight & 1.000 & 0.500 & \\
$\begin{array}{l}\text { Vulnerability } \\
\text { Agricultural Occupation }\end{array}$ & 0.485 & $\begin{array}{c}\text { Frischen et al. (2020), Meza et al. } \\
(2019)\end{array}$ \\
$\begin{array}{l}\text { Total Index Weight } \\
\text { Exposure }\end{array}$ & $\begin{array}{l}\text { Average Household Income } \\
\text { Land Use }\end{array}$ & 0.515 & \\
& Elevation & 0.740 & $\begin{array}{c}\text { Dayal et al. (2018), Frischen et al. } \\
\text { (2020), Meza et al. (2019) }\end{array}$ \\
Total Index Weight & 1.000 & 0.260 & \\
\hline
\end{tabular}

\section{Appendix 4}

Fuzzy Gamma Overlay mathematical equations used to calculate final drought risk index maps from hazard, vulnerability, and exposure index maps.

Methodology is consistent with Dayal et al. (2018). The Fuzzy Gamma Overlay function uses the algebraic product of fuzzy SUM and fuzzy PRODUCT effects, both raised to the power of gamma (generic gamma value of 0.9 was used). Equations (4) and (5) outline the mathematics involved.

$$
\mu_{\text {gamma }}=\left(\mu_{\text {sum }}\right)^{\gamma} \times\left(\mu_{\text {product }}\right)^{1-\gamma},
$$

where $\mu_{\text {gamma }}$ is the fuzzy membership function calculates, $\gamma$ is the gamma value of $0.9 i$; $\mu_{\text {sum }}$ is the fuzzy algebraic SUM and $\mu_{\text {product }}$ is the fuzzy algebraic PRODUCT that is mathematically expressed in Eq. (5).

$$
\mu_{\text {sum }}=1-\prod_{i=1}^{n}\left(1-\mu_{i}\right) \text { and } \mu_{\text {product }}=1-\prod_{i=1}^{n}\left(\mu_{i}\right),
$$

where $\mu_{i}$ is the fuzzy membership for the drought risk map, and $i$ is the number of map layers combined, in this case three layers (hazard, vulnerability and exposure). 
Acknowledgements Authors express sincere gratitude to the Balonne, Goondiwindi, Maranoa, Murweh and Paroo farming communities of the Northern MDB for their valuable input to this research.

\section{Declarations}

Conflict of Interest The authors declare that they have no conflict of interest.

\section{References}

Abel N et al (2016) Building resilient pathways to transformation when "no one is in charge": insights from Australia's Murray-Darling Basin. Ecol Soc. https://doi.org/10.5751/es-08422-210223

Adeyinka AA, Krishnamurti C, Maraseni TN, Chantarat S (2016) The viability of weather-index insurance in managing drought risk in rural Australia. Int J Rural Manag 12:125-142. https://doi.org/10.1177/ 0973005216660897

Asghari A, Kuleshov Y, Watkins A, Brardwaj J, Aitkenhead I (2021) Improving drought resilience in Northern Murray-Darling Basin farming communities: is forecast-based financing suitable? NHAZD20-01240 (accepted)

Australian Bureau of Agricultural and Resource Economics and Sciences (ABARES) (2011) Modelling the economic effects of the Murray-Darling Basin Plan. Australian Bureau of Agricultural and Resource Economics and Sciences, Canberra, Australia

Australian Bureau of Statistics (ABS) (1988) Drought in Australia. https://www.abs.gov.au/ausstats/abs@ . nsf/lookup/1301.0feature\%20article151988 Accessed 25 Aug 2020

Australian Bureau of Statistics (ABS) (2017) Census of population and housing, 1 edn. Commonwealth of Australia, Canberra

Bhardwaj J, Kuleshov Y, Watkins A, Aitkenhead I, Asghari A (2021) Building capacity for an Integrated user-centred early warning system (I-EWS) for drought in the Northern Murray Darling Basin. Nat Hazards 107(1):1-26. https://doi.org/10.1007/s11069-021-04575-2

Bodner G, Nakhforoosh A, Kaul H-P (2015) Management of crop water under drought: a review. Agron Sustain Dev 35:401-442. https://doi.org/10.1007/s13593-015-0283-4

Bureau of Meteorology (2014) Map 1. The key climate groups, 1 edn. Commonwealth of Australia, Melbourne

Bureau of Meteorology (2019) Special climate statement 70 update-drought conditions in Australia and impact on water resources in the Murray-Darling Basin. Bureau of Meteorology, Melbourne

Bureau of Meteorology (2020) Special Climate Statement 70 update-drought conditions in Australia and impact on water resources in the Murray-Darling Basin. the Bureau of Meteorology, Melbourne

Bureau of Meteorology and CSIRO (2020) State of the climate 2020. http://www.bom.gov.au/state-of-theclimate/

Byrnes R (2015) Queensland Drought Queensland Government, Queensland

Chua Z-W, Kuleshov Y, Watkins AB (2020) Drought detection over papua new guinea using satellitederived products. Remote Sens. https://doi.org/10.3390/rs12233859

Cobon DH et al (2009) The climate change risk management matrix for the grazing industry of northern Australia. Rangel J 31:31-49

Connell D, Grafton RQ (2011) Water reform in the Murray-Darling Basin. Water Resour Res. https://doi. org/10.1029/2010wr009820

Crase L, Dollery B, Wallis J (2005) Community consultation in public policy: the case of the Murray-Darling Basin of Australia. Aust J Polit Sci 40:221-237. https://doi.org/10.1080/10361140500129990

Crimp SJ et al (2010) Managing Murray-Darling Basin livestock systems in a variable and changing climate: challenges and opportunities. Rangel J 32:293-304

Dayal KS, Deo RC, Apan AA (2018) Spatio-temporal drought risk mapping approach and its application in the drought-prone region of south-east Queensland, Australia. Nat Hazards 93:823-847. https://doi. org/10.1007/s11069-018-3326-8

Department of Environment and Science (2019) State-wide land use map. State of Queensland, Brisbane

Department of Industry Science Energy and Resources (2020) QLD Local Government Areas-PSMA Administrative Boundaries. Commonwealth of Australia, Canberra

Department of Natural Resources Mines and Energy (2020) Queensland topographic map state of Queensland, Brisbane 
Docker B, Robinson I (2014) Environmental water management in Australia: experience from the MurrayDarling Basin. Int J Water Resour Dev 30:164-177. https://doi.org/10.1080/07900627.2013.792039

Environmental Systems Research Institute (ESRI) Inc. (2019) ArcGIS Pro, 10.7.1 edn. Environmental Systems Research Institute (ESRI) Inc., Redlands

Fallon AL, Villholth KG, Conway D, Lankford BA, Ebrahim GY (2019) Agricultural groundwater management strategies and seasonal climate forecasting: perceptions from Mogwadi (Dendron), Limpopo, South Africa. J Water Clim Chang 10:142-157. https://doi.org/10.2166/wcc.2018.042

Frischen J, Meza I, Rupp D, Wietler K, Hagenlocher M (2020) Drought risk to agricultural systems in Zimbabwe: a spatial analysis of hazard, exposure, and vulnerability. Sustainability 12:752

Goondiwindi Regional Council (2020) Drought management plan. GRC Provider, Goondiwindi

Hart BT (2016) The Australian Murray-Darling Basin Plan: challenges in its implementation (part 1). Int J Water Resour Dev 32:819-834. https://doi.org/10.1080/07900627.2015.1083847

Ho E (2018) Criteria-based ranking (CBR): a comprehensive process for selecting and prioritizing monitoring indicators. MethodsX 5:1324-1329. https://doi.org/10.1016/j.mex.2018.10.015

Huang L, Yang P, Ren S (2014) The vulnerability assessment method for Beijing Agricultural Drought. In: Li D, Chen Y (eds) Computer and computing technologies in agriculture VII. Springer, Berlin, pp 269-280

International Research Institute for Climate and Society (IRI) (2020) IRI Analyses SPI: standardized Precipitation Index analyses of multiple global precipitation datasets, 1 edn. International Research Institute for Climate and Society (IRI), Palisades

IPCC (2012) Managing the risks of extreme events and disasters to advance climate change adaptation. In: Field CB, Barros V, Stocker TF, Qin D, Dokken DJ, Ebi KL, Mastrandrea MD, Mach KJ, Plattner G-K, Allen SK, Tignor M, Midgley PM (eds) A special report of working groups I and II of the intergovernmental panel on climate change. Cambridge University Press, Cambridge, United Kingdom and New York, NY, USA, p 582

Irmak $\mathrm{S}$ et al (2012) Large-scale on-farm implementation of soil moisture-based irrigation management strategies for increasing maize water productivity. Trans ASABE 55:881-894. https://doi.org/10. $13031 / 2013.41521$

Kaushal M, Wani SP (2016) Plant-growth-promoting rhizobacteria: drought stress alleviators to ameliorate crop production in drylands. Ann Microbiol 66:35-42

Kiem AS (2013) Drought and water policy in Australia: challenges for the future illustrated by the issues associated with water trading and climate change adaptation in the Murray-Darling Basin. Glob Environ Chang 23:1615-1626. https://doi.org/10.1016/j.gloenvcha.2013.09.006

Kirby M, Bark R, Connor J, Qureshi ME, Keyworth S (2014) Sustainable irrigation: how did irrigated agriculture in Australia's Murray-Darling Basin adapt in the Millennium Drought? Agric Water Manag 145:154-162. https://doi.org/10.1016/j.agwat.2014.02.013

Korada N, Sekac T, Jana S, Pal D (2018) Delineating drought risk areas using remote sensing and geographic information systems - a case study of Western Highlands Province, Papua New Guinea European. J Eng Technol Res 3:103-110

Kuleshov Y, Kurino T, Kubota T, Tashima T, Xie P (2019) WMO space-based weather and climate extremes monitoring demonstration project: first outcomes of regional cooperation on drought and heavy precipitation monitoring for Australia and Southeast Asia. https://doi.org/10.5772/intechopen.85824

Kuleshov Y et al (2020) Climate risk and early warning systems (CREWS) for Papua New Guinea. https:// doi.org/10.5772/intechopen.85962

Marsh CR (2018) Productivity commission inquiry—effectiveness of the implementation of the Basin Plan. Balonne Shire Council, St George

Meza I, Hagenlocher M, Naumann G, Vogt J, Frischen J (2019) Drought vulnerability indicators for globalscale drought risk assessments. Publications Office of the European Union Luxembourg

Nagarajan R, Ganapuram S (2015) Micro-level drought vulnerability assessment using standardised precipitation index, standardised water-level index, remote sensing and GIS.

Nasrollahi M, Khosravi H, Moghaddamnia A, Malekian A, Shahid S (2018) Assessment of drought risk index using drought hazard and vulnerability indices. Arab J Geosci 11:606. https://doi.org/10. 1007/s12517-018-3971-y

National Oceanic and Atmospheric Administration (NOAA) (2020) Australia-Vegetation Health Index (VHI): Current Week and One Year Ago, 2020. Center for Satellite Applications and Research (STAR), Maryland

Nguyen-Huy T, Kath J, Shahbaz M, Cobon D, Stone G, Stone R (2020) Integrating El Niño-Southern Oscillation information and spatial diversification to minimize risk and maximize profit for Australian grazing enterprises. Agron Sustain Dev. https://doi.org/10.1007/s13593-020-0605-z 
Oliver TH, Morecroft MD (2014) Interactions between climate change and land use change on biodiversity: attribution problems, risks, and opportunities. Wires Clim Chang 5:317-335

Otkin JA, Shafer M, Svoboda M, Wardlow B, Anderson MC, Hain C, Basara J (2015) Facilitating the use of drought early warning information through interactions with agricultural stakeholders. Bull Am Meteor Soc 96:1073-1078. https://doi.org/10.1175/BAMS-D-14-00219.1

Paneque P (2015) Drought management strategies in Spain. Water 7:6689-6701. https://doi.org/10.3390/ w7126655

Phelps D, Kelly D (2019) Overcoming drought vulnerability in rangeland communities: lessons from central-western Queensland. Rangel J 41:251-270. https://doi.org/10.1071/RJ18052

Pittock J, Connell D (2010) Australia demonstrates the planet's future: water and climate in the MurrayDarling Basin. Int J Water Resour Dev 26:561-578. https://doi.org/10.1080/07900627.2010.519522

Power B, Cacho OJ (2014) Identifying risk-efficient strategies using stochastic frontier analysis and simulation: an application to irrigated cropping in Australia. Agric Syst 125:23-32. https://doi.org/10. 1016/j.agsy.2013.11.002

Pulwarty RS, Sivakumar MVK (2014) Information systems in a changing climate: early warnings and drought risk management. Weather Clim Extremes 3:14-21. https://doi.org/10.1016/j.wace.2014. 03.005

Quiggin J, Adamson D, Chambers S, Schrobback P (2010) Climate change uncertainty, and adaptation: the case of irrigated agriculture in the Murray-Darling Basin in Australia. Can J Agric Econ/revue Canadienne D'agroeconomie 58:531-554. https://doi.org/10.1111/j.1744-7976.2010.01200.x

Qureshi ME, Ahmad MD, Whitten SM, Reeson A, Kirby M (2018) Impact of climate variability including drought on the residual value of irrigation water across the Murray-Darling Basin, Australia. Water Econ Policy 4:2382-6258

Rahmati O et al (2020) Capability and robustness of novel hybridized models used for drought hazard modeling in southeast Queensland, Australia. Sci Total Environ 718:134656. https://doi.org/10. 1016/j.scitotenv.2019.134656

Raikes J, Smith TF, Jacobson C, Baldwin C (2019) Pre-Disaster planning and preparedness for floods and droughts: a systematic review. Int J Disaster Risk Reduct 38:101207. https://doi.org/10.1016/j. ijdrr.2019.101207

Saha DK, Kar A, Roy MM (2012) Indicators of drought vulnerability for assessing coping mechanism in arid Western Rajasthan. Ann Arid Zone 51:1-9

Santos JR, Pagsuyoin ST, Herrera LC, Tan RR, Yu KD (2014) Analysis of drought risk management strategies using dynamic inoperability input-output modeling and event tree analysis. Environ Syst Decis 34:492-506. https://doi.org/10.1007/s10669-014-9514-5

Sena A, Ebi KL, Freitas C, Corvalan C, Barcellos C (2017) Indicators to measure risk of disaster associated with drought: implications for the health sector. PLoS ONE 12:e0181394-e0181394. https:// doi.org/10.1371/journal.pone.0181394

Sharafi L, Zarafshani K, Keshavarz M, Azadi H, Van Passel S (2020) Drought risk assessment: towards drought early warning system and sustainable environment in Western Iran. Ecol Indic 114:106276. https://doi.org/10.1016/j.ecolind.2020.106276

Stafford Smith DM, McKeon G, Watson I, Henry BK, Stone G, Hall W, Howden S (2008) Learning from episodes of degradation and recovery in variable Australian rangelands. Proc Natl Acad Sci USA 104:20690-20695. https://doi.org/10.1073/pnas.0704837104

Svoboda M, Fuchs B (2016) Handbook of drought indicators and indices

Uddameri V, Singaraju S, Hernandez EA (2019) Is Standardized Precipitation Index (SPI) a useful indicator to forecast groundwater droughts?-Insights from a Karst Aquifer. JAWRA J Am Water Resour as 55:70-88. https://doi.org/10.1111/1752-1688.12698

Van Lanen H et al (2017) Climatological risk: droughts, pp 271-293

Wheeler S, Loch A, Zuo A, Bjornlund H (2014) Reviewing the adoption and impact of water markets in the Murray-Darling Basin, Australia. J Hydrol 518:28-41. https://doi.org/10.1016/j.jhydrol.2013. 09.019

White DH, Walcott JJ (2009) The role of seasonal indices in monitoring and assessing agricultural and other droughts: a review. Crop Pasture Sci 60:599-616

White WB, Gershunov A, Annis JL, McKeon G, Syktus J (2004) Forecasting Australian drought using Southern Hemisphere modes of sea-surface temperature variability. Int J Climatol 24:1911-1927

Wilhelmi OV, Wilhite DA (2002) Assessing vulnerability to agricultural drought: a Nebraska case study. Nat Hazards 25:37-58. https://doi.org/10.1023/A:1013388814894

Wilhite DA (2005) Drought policy and preparedness: The Australian experience in an international context. In: Botterill LC, Wilhite DA (eds) From disaster response to risk management: Australia's national drought policy. Springer, Dordrecht, pp 157-176. https://doi.org/10.1007/1-4020-3124-6_12 
Williges K, Mechler R, Bowyer P, Balkovic J (2017) Towards an assessment of adaptive capacity of the European agricultural sector to droughts. Clim Serv 7:47-63. https://doi.org/10.1016/j.cliser.2016.10. 003

Yin Y, Zhang X, Lin D, Yu H, Wang J, Shi P (2014) GEPIC-V-R model: A GIS-based tool for regional crop drought risk assessment. Agric Water Manag 144:107-119. https://doi.org/10.1016/j.agwat.2014.05. 017

Zhang D, Wang G, Zhou H (2011) Assessment on agricultural drought risk based on variable fuzzy sets model. Chin Geogra Sci 21:167. https://doi.org/10.1007/s11769-011-0456-2

Publisher's Note Springer Nature remains neutral with regard to jurisdictional claims in published maps and institutional affiliations.

\section{Authors and Affiliations}

\section{Isabella Aitkenhead ${ }^{1,2} \cdot$ Yuriy Kuleshov Ka, $^{2}$ - Andrew B. Watkins ${ }^{2}$. Jessica Bhardwaj ${ }^{1,2} \cdot$ Atifa Asghari ${ }^{1,2}$}

1 Monash University, Clayton, VIC, Australia

2 Bureau of Meteorology, Docklands, VIC, Australia

3 Royal Melbourne Institute of Technology (RMIT) University, Melbourne, VIC, Australia

4 The University of Melbourne, Parkville, VIC, Australia 